\title{
CORRECTION
}

\section{Correction to: Colored and Translucent Chalcogenide-Oxide Nanocomposite Films Prepared by Spin Coating and Reflow Processes}

\author{
Hye Ryeon Yoon ${ }^{1} \cdot$ Yoon Ee Jo ${ }^{1} \cdot$ Seung-Yun Lee ${ }^{1}$
}

Published online: 22 April 2021

(c) The Korean Institute of Electrical and Electronic Material Engineers 2021

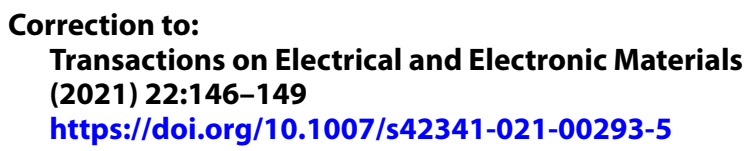

Unfortunately, the original publication of the article was published without keywords. The keywords are given in this correction.

\section{Keywords}

Composite

Chalcogenide

Nanoparticle

Spin coating

Zirconia

The original article has been corrected.

Publisher's Note Springer Nature remains neutral with regard to jurisdictional claims in published maps and institutional affiliations.

The original article can be found online at https://doi.org/10.1007/ s42341-021-00293-5.

Seung-Yun Lee

sy_lee@hanbat.ac.kr

1 Department of Materials Science and Engineering, Hanbat National University, Daejeon 34158, Republic of Korea 